\title{
Sexual Outcomes and Motherhood Plans of The Mayer Rokitansky Küster Hauser Syndrome Patients Operated with Uncu Modified Remnant-Supported Laparoscopic Double-Layer Peritoneal Pull-Down Vaginoplasty Technique
}

\author{
Kiper Aslan ${ }^{1}$, Tansu Gurbuz², Adnan Orhan², Isil Kasapoglu², Kemal Ozerkan², and \\ Gurkan Uncu ${ }^{3}$ \\ ${ }^{1}$ Affiliation not available \\ ${ }^{2}$ Uludag University Faculty of Medicine \\ ${ }^{3}$ Uludag University School of Medicine
}

June 29, 2021

\begin{abstract}
Objective: To determine the sexual outcomes and motherhood plans of the Mayer Rokitansky Küster Hauser (MRKH) Syndrome patients operated with Uncu Modified Remnant-Supported Laparoscopic Double-Layer Peritoneal Pull-Down Vaginoplasty operation Design: Cohort Study Setting: Tertiary University Hospital Patients: Women with MRKH syndrome Methods: This study involves the patients with MRKH syndrome who underwent Uncu Modified Remnant-Supported Laparoscopic DoubleLayer Peritoneal Pull-Down Vaginoplasty Operation between the years 2008-2020. The first step of the study is about our surgical technique outcomes. The second step consists of long-term results for sexual functioning which was assessed by female sexual function index (FSFI) survey and motherhood plans by another survey. Main Outcome Measure: FSFI and Motherhood Survey Results Results Total 42 patients with MRKH syndrome underwent vaginoplasty operation. At least one year after surgery all patients was physically examined. The mean vaginal length was $8.4+1.9 \mathrm{~cm}$. The mean FSFI score was $31.5+$ 3.9 (min:24-max:36) Thirty-six of the patients answered a survey about motherhood. Thirty-one of the patients (86\%) had a desire for motherhood. Most of the patients $(21 / 31-68 \%)$ choose uterine transplantation as a first option. Three of the patients (9.6\%) choose mater option and seven patients $(22.5 \%)$ wants to be a mother by adoption. Conclusion: Uncu Modified RemnantSupported Laparoscopic Double-Layer Peritoneal Pull-Down Vaginoplasty Operation is a satisfactory option for patients with MRKH syndrome with high FSFI scores and low complication rates. But creating only a neovagina is not enough for these patients, because of nearly $70 \%$ motherhood desire by uterine transplantation.
\end{abstract}

Title: Sexual Outcomes and Motherhood Plans of The Mayer Rokitansky Küster Hauser Syndrome Patients Operated with Uncu Modified Remnant-Supported Laparoscopic Double-Layer Peritoneal Pull-Down Vaginoplasty Technique

\section{Authors:}

Kiper ASLAN M.D. ${ }^{1}$, Tansu Bahar Gurbuz M.D. ${ }^{1}$, Adnan Orhan Assoc. Prof. ${ }^{1}$, Isil Kasapoglu Assoc.Prof. ${ }^{1}$, Kemal Ozerkan Prof. ${ }^{1}$, Gurkan Uncu Prof. ${ }^{1}$

\section{Affiliation:}

1-Bursa Uludag University School of Medicine Department of Obstetrics and Gynecology, Minimally Invasive Surgery Unit. 
Gorukle - Bursa / Turkey, Postal Code:16285

Kiper Aslan kiperaslan@yahoo.com.tr ORCID: 0000-0002-9277-7735

Tansu Bahar Gurbu. drtnsugurbuz@gmail.com ORCID: 0000-0002-8315-1044

Adnan Orhan dr.adnan.orhan@hotmail.com ORCID: 0000-0002-7558-8166

Isil Kasapoglu. kasapogluisil@hotmail.com ORCID: 0000-0002-1953-2475

Kemal Ozerkan doctorkemal@yahoo.com ORCID: 0000-0003-1460-6524

Gurkan Uncu guncu@gurkanuncu.org ORCID: 0000-0001-7660-8344

Running Title : Uncu Modified Laparoscopic Neovaginoplasty

Corresponding Author:

Kiper Aslan M.D.

Bursa Uludag University Faculty of Medicine, Dept. of Obstetrics \& Gynecology, Minimally Invasive Surgery Unit.

Görükle/Bursa/Turkey Postal Code: 16285

kiperaslan@yahoo.com.tr

Mobile: +905548127272

Word Count: 2937

Abstract:

Objective: To determine the sexual outcomes and motherhood plans of the Mayer Rokitansky Küster Hauser (MRKH) Syndrome patients operated with Uncu Modified Remnant-Supported Laparoscopic Double-Layer Peritoneal Pull-Down Vaginoplasty operation

Design: Cohort Study

Setting: Tertiary University Hospital

Patients: Women with MRKH syndrome

Methods: This study involves the patients with MRKH syndrome who underwent Uncu Modified RemnantSupported Laparoscopic Double-Layer Peritoneal Pull-Down Vaginoplasty Operation between the years 20082020. The first step of the study is about our surgical technique outcomes. The second step consists of longterm results for sexual functioning which was assessed by female sexual function index (FSFI) survey and motherhood plans by another survey.

Main Outcome Measure : FSFI and Motherhood Survey Results

Results Total 42 patients with MRKH syndrome underwent vaginoplasty operation. At least one year after surgery all patients was physically examined. The mean vaginal length was $8.4+1.9 \mathrm{~cm}$. The mean FSFI score was $31.5+3.9$ (min:24-max:36) Thirty-six of the patients answered a survey about motherhood. Thirty-one of the patients (86\%) had a desire for motherhood. Most of the patients $(21 / 31-68 \%)$ choose uterine transplantation as a first option. Three of the patients (9.6\%) choose mater option and seven patients $(22.5 \%)$ wants to be mother by adoption.

Conclusion: Uncu Modified Remnant-Supported Laparoscopic Double-Layer Peritoneal Pull-Down Vaginoplasty Operation is a satisfactory option for patients with MRKH syndrome with high FSFI scores and low complication rates. But creating only a neovagina is not enough for these patients, because of nearly $70 \%$ motherhood desire by uterine transplantation. 
Key Words : Mullerian Agenesis, Laparoscopy, Neovaginoplasty, Uterine Transplantation, Mayer Rokitansky Küster Hauser Syndrome

Conflict of Interest: The authors report there is no conflict of interest

Funding: None

\section{Tweetable Abstract:}

Uncu modified laparoscopic neovaginoplasty operation is a satisfactory surgical approach for MayerRokitansky-Küster-Hauser Syndrome patients with high sexual and functional outcomes.

\section{Introduction}

Since Mayer-Rokitansky-Küster-Hauser syndrome was first described ${ }^{1}$, numerous vaginoplasty methods have been invented. ACOG (American College of Obstetrics and Gynecology) advises vaginal non-surgical, selfdilatation method as first-line treatment in MRKH patients. ${ }^{2}$ Nevertheless, in some cases, anatomic and sexual results are not satisfactory. Patients may not be capable of sexual intercourse with self-dilatation. Also, this method requires long-term exercises and patient compliance. Thus, surgical options may be helpful for patient satisfaction. There are mainly three surgical methods for neovagina creation. The first approach is the Mc Indoe method $^{3}$, a vaginal surgery consisting of insertion a created vagina (with numerous materials like an autologous skin graft, invitro cultured vaginal tissue, acellular collagen, amniotic membrane, fish skin, buccal mucosa) into the dissected pouch between rectum and bladder. ${ }^{4-11}$ The second approach is the Vechietti operation which requires long-term abdomen-vaginal traction with special instruments. ${ }^{12-14}$ This method is including both vaginal and abdominal (laparotomy or laparoscopy) surgery. The last method is Davydov vaginoplasty. In this technique, a canal is created between the blind vaginal introitus and the peritoneal cavity by dissection. The parietal peritoneum is pulled down by vaginal approach, and the vaginal cuff is closed with purse-string sutures. ${ }^{15}$ With our previously described Uncu Modified Remnant-Supported Laparoscopic Double-Layer Peritoneal Pull-Down Vaginoplasty Operation, we perform all surgical steps laparoscopically, and we are supporting the vaginal cuff with paramesonephric remnants by second layer suturation. ${ }^{16}$ There have been over ten years since our first case, and we noticed that patients operated by our technique are in a desire for motherhood. There are seventeen published live births by uterine transplantation ${ }^{17}$ and numerous live births by maternal surrogacy from different countries globally for MRKH patients. Also, child adoption is an option for these patients.

In this survey study, we aimed to show the current anatomic and sexual results of our operated cases with MRKH and discuss motherhood options with survey results.

\section{Materials \& Methods}

This study was conducted at a tertiary university hospital. The ethical committee of the university approved the study. Patients with MRKH syndrome who underwent Uncu Modified Remnant-Supported Laparoscopic Double-Layer Peritoneal Pull-Down Vaginoplasty Operation were enrolled in the study between 2008 and 2020. Patients underwent a detailed examination before the operation. Secondary sexual characteristics, chromosomal analysis, urinary system abnormalities, detailed imagination for uterine remnants of the Mullerian ducts were evaluated. All patients operated by six senior surgeons who were experienced in Uncu Modified Remnant-Supported Laparoscopic Double-Layer Peritoneal Pull-Down Vaginoplasty Operation. The same technique, which was described in our previous study, was used in all operations. ${ }^{16}$

Uncu Modified Remnant-Supported Laparoscopic Double-Layer Peritoneal Pull-Down Vaginoplasty

The technique involves vaginal and laparoscopic approaches. After laparoscopic set-up and visualization of the pelvis, the vaginal approach begins with the vaginal introitus's transverse incision. After careful dissection between the bladder and rectum through the Douglas pouch, peritoneal entry is applied by laparoscopic dissection. Later than, opened canal through the peritoneum was vaginally gradually dilated with sterilized acrylic molds. After the largest mold is replaced, No.1 Vicryl sutures are laparoscopically placed through the peritoneum's anterior, posterior, left, and right sides. All four sutures are pulled down through the 
vagina to stitch the lower edges of the parietal peritoneum to the vaginal opening. To form the vaginal cuff, firstly uterine remnant is divided into two parts by bipolar energy, then starting from one remnant parietal peritoneum is cut by scissors through the bladder peritoneum and through to the other remnant. After dividing the other remnant into two parts, the posterior parietal peritoneum is cut through the rectum and the other remnant. The peritoneal flap is mobilized and stripped of the underlying tissue by sharp dissection with scissors and traction- counter-traction. The prepared peritoneal flap is lied over the vaginal mold and stitched with a purse-string suture using $2 / 0$ Vicryl. A second peritoneal layer is created using the lower edge of the in situ parietal peritoneum. A second purse-string suture was placed. The second suture is passed through the lateral halves of the divided rudimentary horns as well as the medial halves sitting on the neovaginal vault. This connection is made to provide further support to the vaginal dome.

Following double-layer closure of the vaginal vault, lower edges of the peritoneum, which is pulled down at the beginning of the surgery, are stitched to the introitus mucosa at 4 points: anterior, posterior, and two edges. The largest mold is placed into the neovagina at the end of the operation. After the last laparoscopic view of the pelvis, the operation is completed. (Figure-1)

\section{Postoperative Care}

Patients are allowed for mobilization 24 hours after surgery. The surgeon applies the first mold exercise to teach the patient how to make it. Patients are discharged on the third day after the operation. Patients are informed with a written guide for mold exercises and doctor visits. The patient compliance, vaginal length \& width, epithelization, and complications are noted at each visit. Patients are allowed for sexual intercourse at the fourth month after surgery if there is no complication for coitus. At one year after surgery, the final vaginal length is measured, and the patient is dropped out from follow-up.

\section{Survey for Sexual outcomes and Motherhood Desire}

A resident of our obstetrics and gynecology department was employed for the survey. All the patients were called and invited for the survey after an explanation of the content. The first survey was the Female Sexual Function Index (FSFI). This index is a validated and commonly used survey worldwide. ${ }^{18}$ It is a brief questionnaire with a measure of sexual functioning in women. It contains nineteen questions. It was developed for the specific purpose of assessing domains of sexual functioning (e.g., sexual arousal, orgasm, satisfaction, pain) in clinical trials. The maximum point is 36 with the highest satisfaction, and the minimum is 2 . There is a threshold at 26.55 which means that all values below are classed as indicating female sexual dysfunction.

The second survey was about motherhood desire. We formed a questionnaire that consisted of two questions. The first question was about having a motherhood desire in the future, whether yes or no. The second question was about the motherhood method. If the patient wanted to be a mother, which way would she prefer? The first option was Uterine Transplantation, the second one was maternal surrogacy, and the last one is child adoption. The two testicular-feminization patients were not enrolled in the motherhood survey

\section{Results}

A total of 42 women with MRKH syndrome underwent surgery with Uncu Modified Remnant-Supported Laparoscopic Double-Layer Peritoneal Pull-Down Vaginoplasty Operation. The mean age was $27.3+4.7$ years, and the mean body mass index was $23.4+3.6 \mathrm{~kg} / \mathrm{m} 2$. Two of the 42 patients' karyotype was $46 \mathrm{XY}$ and diagnosed with testicular feminization. The other forty patients had normal female karyotype. Thirty-six of the patients had a normal urinary scan. Three patients were diagnosed with unilateral renal agenesis, and three patients were diagnosed with the double ureter. There were four perioperative complications. Three of the complications were bladder injury during the vaginal dissection through the Douglas pouch. One of the complications was rectum serosa injury which occurred during peritoneal preparation. All the injuries were laparoscopically repaired during the operation. There was no need for a second operation for these patients. There were four long-term complications during follow-up. One patient with vesicovaginal fistula, one patient with rectovaginal fistula, and two patients with vaginal stenosis because of incompliance with regular mold 
exercise. The patient with vesicovaginal fistula was recovered with continued Foley catheterization for two weeks. The patient with rectovaginal fistula was diagnosed three months after surgery. She underwent another operation to repair the fistula and divert a colostomy. The colostomy was closed at six months after the second operation.

The mean vaginal length at one-year control was $8.4+1.9 \mathrm{~cm}$ with enough width for sexual intercourse. A standard speculum could easily be inserted into the vagina of all patients except for the two patients who did not regularly exercise and dropped out from follow-up. The vaginal surface epithelium was completely was formed at one-year control. There was not an obvious external sign of the surgery in any patients.

There were thirty-six patients with a sexual partner and accepted the FSFI survey. The mean FSFI score was $31.5+3.9$ (min:24-max:36)

Five of the 31 patients were not in a desire of motherhood. The other 31 patients answered their motherhood plans. Twenty-one patients $(68 \%)$ wanted to be a mother by uterine transplantation if possible in our country. Three patients $(9.6 \%)$ thought to be a mother by maternal surrogacy after ICSI, and seven patients $(22.5 \%)$ were planning to be a mother by adopting a child.

\section{Discussion}

\section{Main Findings}

In this study, we again showed that laparoscopic paramesonephric remnant supported double-layer peritoneal pull down vaginoplasty - Uncu Modification is a satisfactory option with high FSFI scores and low complication rates in patients with MRKH. Since our first publication ${ }^{16}$, we increased our operated patient number and became a referral center with our experienced surgical team. With the increasing number of MRKH patients in our center from all over the country, we aimed to find a solution for the other major problem beyond sexual intercourse; motherhood. Thus, in this study, we also tried to understand the patients' motherhood desire and found that most patients want to be mothers with a transplanted uterus in their own body.

\section{Interpretation}

There are two significant concerns for MRKH patients after diagnosis. The first one is the ability for sexual intercourse, and the second one is the ability to have a child. For the first one, the solution is creating a functional vagina. The first-line therapy is the self-dilatation technique which requires patient compliance, regular exercises, long-term patience. ${ }^{19-21}$ Surgical treatment is an option when the non-surgical methods are unresponsive, or patients directly request surgery. There are numerous surgical techniques mainly in three subgroups; Mc Indoe, Vechietti, and Davydov surgeries. ${ }^{3,12,15}$

Mc Indoe technique is the historical method that was first used for the creation of a neovagina. This procedure involves the careful dissection of the space between the bladder and rectum and a stent covered with an autologous skin graft placed through the dissected space. Dilatation exercises must continue after surgery to avoid collapsing of the neovagina. There are developed methods like Mc Indoe using different materials instead of skin graft. Small intestine mucosa, absorbable adhesion barrier, buccal mucosa, amnion membrane, peritoneum, tilapia fish skin, in vitro cultured vaginal tissue are the published materials that were used to create a vagina. ${ }^{4-11}$ This technique has a short recovery period because of not involving any abdominal process. However, using graft materials increases the cost of the operation.

The Vechietti technique is based on performing a laparotomy with dissection of the vesicorectal septum and fixation of the vaginal "dilatation olive" using two sutures passing the vaginal stump and after that externalizing the threads to a traction device through the abdominal wall. ${ }^{12}$ With the developing technology, this technique is also developed, and instead of laparotomy, laparoscopy or robotic modified Vechietti techniques were also reported. ${ }^{13-14}$ The traction device is approximately being used for 2-4 weeks. This period may be painful and uncomfortable for the patients, although reaching at least $6 \mathrm{~cm}$ length vagina at the end of the procedure. 
The last procedure is the Davydov operation which is mainly based on pulling down the parietal peritoneum and suturing it to the vaginal introitus. This method has many advantages; firstly, this method has a shorter recovery time than the Vechietti procedure and cost-effective procedure than Vechietti and Mc Indoe operations. Using peritoneum eliminates the possible graft complications like; hairy formation due to skin graft, heavy vaginal discharge due to intestinal graft, foreign body reaction, and granulation for synthetic grafts.

Our Uncu Modified Remnant-Supported Laparoscopic Double-Layer Peritoneal Pull-Down Vaginoplasty Operation procedure seems to provide a robust vaginal dome with remnant supported double-layer suturation, also an adequate vaginal length with a mean length of $8.4 \mathrm{~cm}$ at one-year control. Most of the studies accept enough vaginal length as $6 \mathrm{~cm}$. Beyond the vaginal length, FSFI scores of our patients (mean FSFI; $31.4+3.9$ ) are higher than patients operated either Davydov, Vechietti or Mc Indoe technique. ${ }^{22-26}$ Thus, the first problem of our MRKH patients was solved. Now we need to solve the other major problem, motherhood.

There are two main options for MRKH patients to have children. Also, there may be another option; child adoption. Nevertheless, patients mostly want their own genetical children. The first method is to find a gestational carrier. This method involves IVF\&ICSI procedure, later than embryo transfer to the gestational carrier. There are two forms of surrogacy process; commercial or voluntary. Countries such as France, Germany, Italy, Spain, Portugal, Bulgaria, and Turkey prohibit all forms of surrogacy in our country. In countries including the United Kingdom, Ireland, Denmark, and Belgium, surrogacy is allowed where the surrogated mother is not paid, voluntary. Commercial form is legal in some US states, India, Russia, Ukraine, and Georgia. Some countries have criminalized going to another country for commercial surrogacy, while others permit it. Also, this process may be costly. Moreover, another issue is that the surrogate mother is recognized as the legal mother. This idea is based on ancient Roman law. "Mater semper certa est." ("The mother is always certain") is a Roman-law principle that has the power of praesumptio iuris et de iure, meaning that no counter-evidence can be made against this principle. It provides that the mother of the child is conclusively established, from the moment of birth, by the mother's role in the birth. ${ }^{27}$

Thus, the best choice for having own child for MRKH seems as Uterine Transplantation (UTx) in countries which prohibited all forms of surrogacy. More than 70 UTx was performed worldwide since the first successful UTx from a multiorgan donor in 2012 in Turkey. ${ }^{17,28}$ This patient gave a healthy birth on June 2020 after several embryo transfers. There are another 23 reported live births from UTx worldwide (Sweden, United States (Dallas, Cleveland), Germany, Brazil, Serbia, Czech Republic, China, and India). ${ }^{28}$ There are many reasons for the low numbers of UTx worldwide. Firstly, because of not being a life-saving organ, the uterus transplantation procedure was not investigated as much as other solid organ transplantation procedures. Graft dysfunction risk, increased gestational complications (preterm delivery, fetal growth restriction, hypertensive disorders) compared to the general population, immune-suppression during pregnancy are the general concerns for UTx. However, it's known that fetal congenital abnormality risk is not elevated in transplant pregnancies. ${ }^{29}$ Although these concerns, increasing numbers of live births (mostly from US - Dallas) give us hope for spreading this process.

\section{Strengths and Limitations}

Since the MRKH is a rare condition in healthy population, our study provide the surgical results of high number of these patients and it improves the power of our study. Presence of the same surgical team and surgical technique for all patients, using a globally validated sexual function survey (FSFI) are the strengths of our study. Absence of a control group with another surgical approach either Davydov or Mc Indoe technique limits to interpret our results.

\section{Conclusion}

Uncu modified laparoscopic neovaginoplasty operation is a satisfactory surgical approach for MayerRokitansky-Küster-Hauser Syndrome patients with high sexual and functional outcomes. As our survey results show, most MRKH patients $(70 \%)$ want to be mothers by UTx. Thus, our new investigations should be in this way. With the increasing numbers of uterine transplantation centers worldwide, more MRKH 
patients will realize their motherhood dreams.

\section{Declarations}

\section{Author's Contribution}

G.U. was the founder of the surgical technique. G.U., K.O, I.K, A.O., K.A were the surgeons. K.A was responsible for data collection, data analysis and writing of the first draft of the manuscript. T.B.G was responsible for the patient communication, follow-up and survey. All authors contributed to the writing of the manuscript, made critical comments and approved the final version.

\section{Ethical Statement}

The ethical committee of the Bursa Uludag University approved the study with the number 2021-1/45 on 05.01.2021.

\section{Data Availability}

The data underlying this article can be shared on reasonable request to the corresponding author.

Funding: None.

Conflict of Interest: The authors report that there is no conflict of interest.

\section{References:}

1. Pizzo A, Laganà AS, Sturlese E, Retto G, Retto A, De Dominici R, Puzzolo D. Mayer-rokitanskykuster-hauser syndrome: embryology, genetics and clinical and surgical treatment. ISRN Obstet Gynecol. 2013;2013:628717. doi: 10.1155/2013/628717. Epub 2013 Feb 4. PMID: 23431465; PMCID: PMC3575620.

2. Committee on Adolescent Health Care. ACOG Committee Opinion No. 728: Müllerian Agenesis: Diagnosis, Management, And Treatment. Obstet Gynecol. 2018 Jan;131(1):e35-e42. doi: 10.1097/AOG.0000000000002458. PMID: 29266078.

3. Banister JB, McIndoe AH. Congenital Absence of the Vagina, treated by Means of an Indwelling Skin-Graft. Proc R Soc Med. 1938 Jul;31(9):1055-6. PMID: 19991582; PMCID: PMC2076989.

4. Teng Y, Zhu L, Chong Y, Zeng A, Liu Z, Yu N, Zhang W, Chen C, Wang X. The Modified McIndoe Technique: A Scar-free Surgical Approach for Vaginoplasty With an Autologous Micromucosa Graft. Urology. 2019 Sep;131:240-244. doi: 10.1016/j.urology.2019.05.020. Epub 2019 May 28. PMID: 31150693.

5. Sabatucci I, Palaia I, Marchese C, Muzii L, Morte CD, Giorgini M, Musella A, Ceccarelli S, Vescarelli E, Panici PB. Treatment of the Mayer-Rokitansky-Küster-Hauser syndrome with autologous in vitro cultured vaginal tissue: descriptive study of long-term results and patient outcomes. BJOG. 2019 Jan;126(1):123-127. doi: 10.1111/1471-0528.15477. Epub 2018 Oct 24. PMID: 30230668.

6. Motta GL, Tavares PM, Silva GVM, Berger M, Silva B Neto, Rosito TE. Full-thickness skin mesh graft vaginoplasty: a skin sparing technique. Int Braz J Urol. 2017 Nov-Dec;43(6):1193. doi: 10.1590/S16775538.IBJU.2016.0259. PMID: 28191788; PMCID: PMC5734087.

7. Dias MTPM, Bilhar APM, Rios LC, Costa BA, Lima Júnior EM, Alves APNN, Bruno ZV, Moraes Filho MO, Bezerra LRPS. Neovaginoplasty Using Nile Tilapia Fish Skin as a New Biologic Graft in Patients with Mayer-Rokitansky-Küster-Hauser Syndrome. J Minim Invasive Gynecol. 2020 MayJun;27(4):966-972. doi: 10.1016/j.jmig.2019.09.779. Epub 2019 Sep 20. PMID: 31546063.

8. Vatsa R, Bharti J, Roy KK, Kumar S, Sharma JB, Singh N, Singhal S, Meena J. Evaluation of amnion in creation of neovagina in women with Mayer-Rokitansky-Kuster-Hauser syndrome. Fertil Steril. 2017 Aug;108(2):341-345. doi: 10.1016/j.fertnstert.2017.05.026. Epub 2017 Jun 16. PMID: 28624115.

9. Wu M, Wang Y, Xu J, Dai H, Zhong X, Sun M, Lv C, Xue C. Vaginoplasty With Mesh Autologous Buccal Mucosa in Vaginal Agenesis: A Multidisciplinary Approach and Literature Review. Aesthet Surg J. 2020 Nov 19;40(12):NP694-NP702. doi: 10.1093/asj/sjaa147. PMID: 32498090 
10. Jackson ND, Rosenblatt PL. Use of Interceed Absorbable Adhesion Barrier for vaginoplasty. Obstet Gynecol. 1994 Dec;84(6):1048-50. PMID: 7970464.

11. Rothman D. The use of peritoneum in the construction of a vagina. Obstet Gynecol. 1972 Dec;40(6):8358. PMID: 4564723.

12. Vecchietti G. Neovagina nella sindrome di Rokitansky-Küster-Hauser [Creation of an artificial vagina in Rokitansky-Küster-Hauser syndrome]. Attual Ostet Ginecol. 1965 Mar-Apr;11(2):131-47. Italian. PMID: 5319813.

13. Cezar C, Devassy R, Larbig A, De Wilde RL. Efficacy risks of the minimal-invasive plastic and reconstructive neovagina Vecchietti technique in Mayer-Rokitansky-Küster-Hauser syndrome. GMS Interdiscip Plast Reconstr Surg DGPW. 2014 Dec 10;3:Doc13. doi: 10.3205/iprs000054. PMID: 26504724; PMCID: PMC4582508.

14. Yang X, Liang J, Li W, Chen B, Sun X, Xie Z. Modified Vecchietti vaginoplasty using self-made single-port laparoscopy in Mayer-Rokitansky-Küster-Hauser syndrome. Fertil Steril. 2021 Jan 15:S00150282(20)32503-6. doi: 10.1016/j.fertnstert.2020.10.001. Epub ahead of print. PMID: 33461758.

15. Davydov SN, Zhvitiashvili OD. Formation of vagina (colpopoiesis) from peritoneum of Douglas pouch. Acta Chir Plast. 1974;16(1):35-41. PMID: 4141200.

16. Uncu G, Özerkan K, Ata B, Kasapoğlu I, Atalay MA, Orhan A, Aslan K. Anatomic and Functional Outcomes of Paramesonephric Remnant-Supported Laparoscopic Double-Layer Peritoneal Pull-Down Vaginoplasty Technique in Patients with Mayer-Rokitansky-Küster-Hauser Syndrome: Uncu Modification. J Minim Invasive Gynecol. 2018 Mar-Apr;25(3):498-506. doi: 10.1016/j.jmig.2017.10.015. Epub 2017 Oct 19. PMID: 29056568.

17. Jones BP, Kasaven L, Vali S, Saso S, Jalmbrant M, Bracewell-Milnes T, Thum MY, Quiroga I, Friend P, Diaz-Garcia C, Ghaem-Maghami S, Yazbek J, Lees C, Testa G, Johannesson L, Jones B, Smith JR. Uterine Transplantation; Review of Livebirths and Reproductive Implications. Transplantation. 2020 Dec 10. doi: 10.1097/TP.0000000000003578. Epub ahead of print. PMID: 33315758.

18. Rosen R, Brown C, Heiman J, Leiblum S, Meston C, Shabsigh R, Ferguson D, D'Agostino R Jr. The Female Sexual Function Index (FSFI): a multidimensional self-report instrument for the assessment of female sexual function. J Sex Marital Ther. 2000 Apr-Jun;26(2):191-208. doi: 10.1080/009262300278597. PMID: 10782451

19. Willemsen WN, Kluivers KB. Long-term results of vaginal construction with the use of Frank dilation and a peritoneal graft (Davydov procedure) in patients with Mayer-Rokitansky-Küster syndrome. Fertil Steril. 2015 Jan;103(1):220-7.e1. doi: 10.1016/j.fertnstert.2014.10.014. Epub 2014 Nov 15. PMID: 25455533.

20. Gargollo PC, Cannon GM Jr, Diamond DA, Thomas P, Burke V, Laufer MR. Should progressive perineal dilation be considered first line therapy for vaginal agenesis? J Urol. 2009 Oct;182(4 Suppl):1882-9. doi: 10.1016/j.juro.2009.03.071. Epub 2009 Aug 20. PMID: 19695600.

21. Patel V, Hakim J, Gomez-Lobo V, Amies Oelschlager AM. Providers' Experiences with Vaginal Dilator Training for Patients with Vaginal Agenesis. J Pediatr Adolesc Gynecol. 2018 Feb;31(1):45-47. doi: 10.1016/j.jpag.2017.07.006. Epub 2017 Aug 4. PMID: 28826904.

22. Zhao X, Wang R, Wang Y, Li L, Zhang H, Kang S. Comparison of two laparoscopic peritoneal vaginoplasty techniques in patients with Mayer-Rokitansky-Küster-Hauser syndrome. Int Urogynecol J. 2015 Aug;26(8):1201-7. doi: 10.1007/s00192-015-2675-z. Epub 2015 May 20. PMID: 25990205.

23. Dong X, Xie Z, Jin H. [Comparison study between Vecchietti's and Davydov's laparoscopic vaginoplasty in Mayer-Rokitansky-Küster-Hauser syndrome]. Zhonghua Fu Chan Ke Za Zhi. 2015 Apr;50(4):278-82. Chinese. PMID: 26080940.

24. Sabatucci I, Palaia I, Marchese C, Muzii L, Morte CD, Giorgini M, Musella A, Ceccarelli S, Vescarelli E, Panici PB. Treatment of the Mayer-Rokitansky-Küster-Hauser syndrome with autologous in vitro cultured vaginal tissue: descriptive study of long-term results and patient outcomes. BJOG. 2019 Jan;126(1):123-127. doi: 10.1111/1471-0528.15477. Epub 2018 Oct 24. PMID: 30230668.

25. Avsar AF, Tas EE, Keskin HL, Yeğin GF. Vaginoplasty Using Human Amniotic Membranes A Report of Five Patients. J Reprod Med. 2016 Sep;61(9-10):483-488. PMID: 30383949. 
26. Fotopoulou C, Sehouli J, Gehrmann N, Schoenborn I, Lichtenegger W. Functional and anatomic results of amnion vaginoplasty in young women with Mayer-Rokitansky-Küster-Hauser syndrome. Fertil Steril. 2010 Jun;94(1):317-23. doi: 10.1016/j.fertnstert.2009.01.154. Epub 2009 Mar 27. PMID: 19328473.

27. Zweigert, K., \& Drobnig, K. (1991). International Encyclopedia of Comparative Law. BRILL. https://books.google.com.tr/books?id=wKPET7pA_4MC

28. Ozkan O, Akar ME, Ozkan O, Erdogan O, Hadimioglu N, Yilmaz M, Gunseren F, Cincik M, Pestereli E, Kocak H, Mutlu D, Dinckan A, Gecici O, Bektas G, Suleymanlar G. Preliminary results of the first human uterus transplantation from a multiorgan donor. Fertil Steril. 2013 Feb;99(2):470-6. doi: 10.1016/j.fertnstert.2012.09.035. Epub 2012 Oct 18. PMID: 23084266.

29. Durst JK, Rampersad RM. Pregnancy in Women With Solid-Organ Transplants: A Review. Obstet Gynecol Surv. 2015 Jun;70(6):408-18. doi: 10.1097/OGX.0000000000000194. PMID: 26115649.

\section{Hosted file}

Table.docx available at https://authorea.com/users/309695/articles/528382-sexual-outcomesand-motherhood-plans-of-the-mayer-rokitansky-k\%C3\%BCster-hauser-syndrome-patientsoperated-with-uncu-modified-remnant-supported-laparoscopic-double-layer-peritoneal-pulldown-vaginoplasty-technique

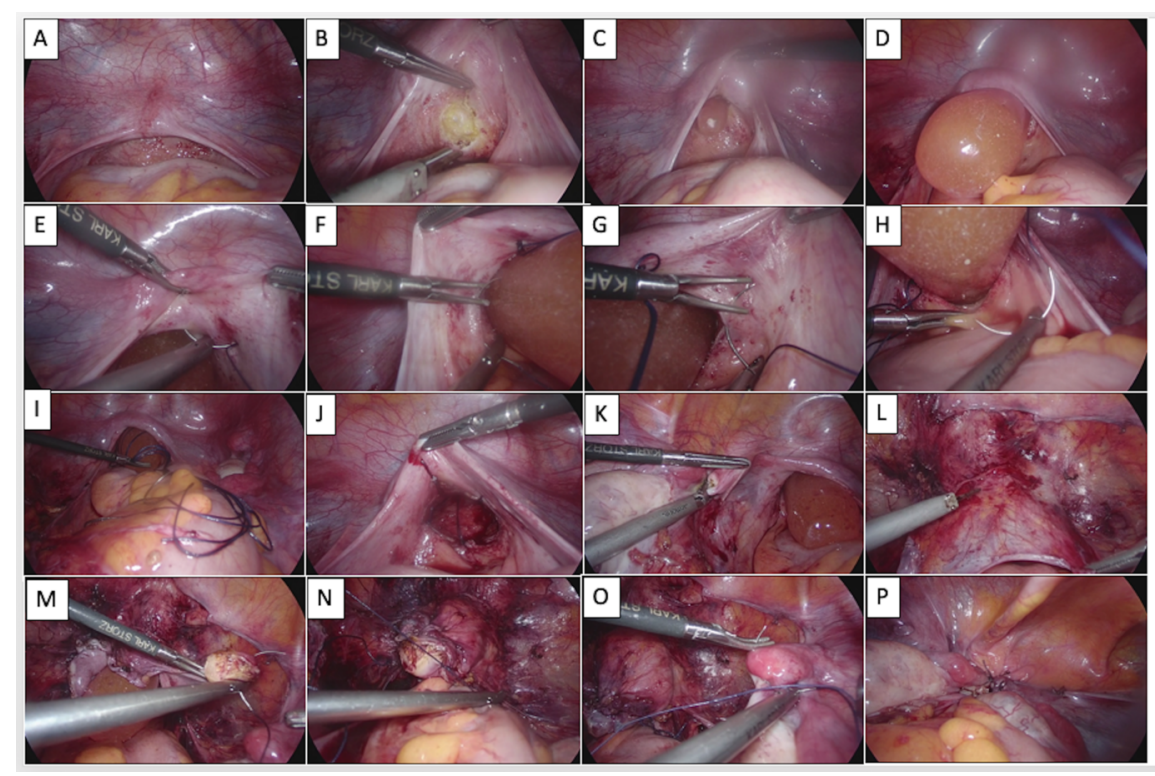

